\title{
Long-term prognostic importance of a single pulmonary wedge pressure measurement after myocardial infarction: a ten-year follow-up study
}

\author{
J.P. Ottervanger ${ }^{a}$, H.A.C.M. Kruijssen ${ }^{b}$, A.W. Hoes* ${ }^{\text {a.c }}$, A. Hofman ${ }^{a}$ \\ ${ }^{a}$ Department of Epidemiology and Biostatistics, 'Department of General Practice, Erasmus University \\ Medical School. Rotterdam. Netherlands \\ ${ }^{b}$ Department of Cardiology, Zuiderziekenhuis Hospital, Rotterdam, Netherlands
}

(Received 14 September 1993; revision accepted 9 November 1993)

\begin{abstract}
To assess the influence on short- and long-term survival of haemodynamic variables measured after acute myocardial infarction, a 10-year prospective follow-up study was undertaken. A total of 304 patients (259 males, 45 females) discharged from hospital after myocardial infarction and under 66 years of age were studied. Haemodynamic variables measured shortly after admittance included pulmonary wedge pressure, mixed venous oxygen saturation, blood pressure and heart rate. In the analysis, adjustments were made for differences in age, gender, clinical parameters and cardiovascular risk factors. Pulmonary wedge pressure was found to be a strong and independent predictor of both short-term and long-term survival. A gradual increase of the 10-year mortality risk with elevated wedge pressure could be demonstrated (relative risk, $1.09 / \mathrm{mmHg} ; 95 \%$ confidence interval, 1.04-1.15). Relative risks of patients in the three highest categories of wedge pressure, $12-15 \mathrm{mmHg}, 15-19 \mathrm{mmHg}$ and $19 \mathrm{mmHg}$ and higher. compared with patients in the lowest category, lower than $12 \mathrm{mmHg}$, were $2.25(95 \% \mathrm{Cl}, 1.11-4.55), 2.43(95 \% \mathrm{Cl}, 1.20-4.92)$ and $2.57(95 \%$ $\mathrm{CI}, 1.04-6.37)$, respectively. The other measured haemodynamic variables were found to be associated with short-term mortality only. In conclusion, haemodynamic measurements after myocardial infarction are of prognostic importance after discharge. A single measurement of an elevated wedge pressure in particular unfavourably influenced both shortterm and long-term survival.
\end{abstract}

Key words: Myocardial infarction; Haemodynamic variables; Pulmonary wedge pressure; Survival; Swan-Ganz catheterisation

\section{Introduction}

In recent years, the beneficial effects associated with the use of Swan-Ganz catheterisation in acute myocardial infarction on selected patient outcomes, including in-hospital mortality and average hospital stay, have been debated $[1,2]$. However. the use of the catheterisation of the

\footnotetext{
* Corresponding author, Department of Epidemiology and Biostatistics, Erasmus University Medical School, P.O. Box 1738.3000 DR Rotterdam, Netherlands. Tel. $(+31-10) 4087365$. Fax $(+31-10) 4087494$
} 
pulmonary artery may provide prognostic information [3-5]. Assessment of factors which affect the prognosis of individual patients after myocardial infarction is potentially useful in patient management, design of clinical trials of therapy and elucidation of the mechanisms leading to death after infarction [6].

Previous studies demonstrated the role of several haemodynamic variables measured early after acute myocardial infarction on subsequent mortality [7-9]. In particular, an elevated wedge pressure was associated with an increased mortality. In these reports, however, the prognostic importance of the haemodynamic variables was evaluated within a limited follow-up period. The influence of these variables on long-term survival remains unknown. Furthermore, most published studies failed to adjust for differences in the other prognostic factors, by using multivariate statistical techniques, and thus the independent role of the haemodynamic measurements on survival was not reported.

Since 1978, the Zuiderziekenhuis Hospital in Rotterdam routinely collects data on early haemodynamic variables, clinical parameters, and cardiovascular risk factors of patients discharged alive after a myocardial infarction. This enabled us to assess the independent long-term prognostic importance of haemodynamic variables.

\section{Patients and methods}

\subsection{Patients}

All patients discharged alive after a diagnosis of acute myocardial infarction from the Zuiderziekenhuis Hospital, Rotterdam between January 1978 and December 1980, and under 66 years of age, were included in the present study, as described previously [10]

The diagnosis acute myocardial infarction was based upon at least two of the following criteria [11]: (1) a recent positive clinical history of chest pain up to a maximum of $12 \mathrm{~h}$ before admission; (2) characteristic changes in the electrocardiogram; (3) peak elevation, i.e. a maximum recorded level, of serum enzymes (CPK, SGOT) of at least 1.5 times the upper limit of normal.
Follow-up data were obtained from official death records and community population registers, indicating whether or not the patients were still alive and if not, the date of death. Information on the vital status up to 5 years after discharge was aváilable for all patients. Follow-up data of 302 patients $(99 \%)$ were available up to 10 years after discharge.

\subsection{Measurements}

Of the 304 survivors at hospital discharge, 262 patients $(86 \%)$ had a 7F Swan-Ganz balloon tipped catheter inserted into the pulmonary artery immediately after admission [12]. The catheters were inserted percutaneously into the antecubital vein or via subclavian puncture, without need of fluoroscopy, by trained medical staff. Pressures were recorded by means of strain gauge transducers. The zero level was $5 \mathrm{~cm}$ below the sternum in the supine position. Mixed venous oxygen saturation was determined from a $1-\mathrm{ml}$ blood sample drawn from the pulmonary artery. Blood pressure was measured with a random zero sphygmomanometer. The heart rate was read from the digital display of the electrocardiographic monitor. Serum total cholesterol concentration was determined by an enzymatic procedure [13], approximately 6 weeks after discharge. Information on a history of hypertension, smoking habits, previous infarction, and diabetes mellitus was collected during an interview, as soon as possible after hospital admittance. History of hypertension was defined as a systolic blood pressure of at least $160 \mathrm{mmHg}$ and/or a diastolic blood pressure of at least 95 $\mathrm{mmHg}$, measured on at least two occasions before admittance, or when patients were currently taking antihypertensive medication for hypertension. Patients were classified as being diabetic only if anti-diabetic drug therapy had been initiated prior to admittance. Patients were classified as smokers if they had regularly smoked at least one cigarette, cigar or pipe per day in the 3 months before admission.

\subsection{Data analysis}

Differences between group means were tested by two-tailed Student's $t$-test. A $\chi^{2}$ statistic was calculated to test differences between proportions. 
To assess the influence of haemodynamic variables on short-term and long-term survival, the followup period was divided into three non-overlapping time intervals: up to 1 year, from 1 year to 5 years and from 5 to 10 years. Differences in haemodynamic variables between survivors and nonsurvivors were adjusted for differences in age (continuous variable) and gender by analysis of covariance. Survival functions were calculated, using the Kaplan-Meier product limit method [14]. The Mantel-Cox (or log-rank) test was applied to evaluate the differences between survival functions. Statistical significance was defined as a $P$ value of less than 0.05 .

Multivariate analysis was performed by fitting Cox's proportional hazards model [15]. All haemodynamic variables were included separately as continuous variables. Odds ratios, which may be interpreted as relative risks (RR), with 95\% confidence intervals $(95 \% \mathrm{Cl})$ were calculated. Pul-

Table 1

Characteristics of 304 patients discharged alive after acute myocardial infarction

\begin{tabular}{|c|c|c|c|}
\hline $\begin{array}{l}\text { Characteristic (unit) } \\
\text { (S.D.) }^{\text {b }}\end{array}$ & $n^{\mathrm{a}}$ & $\begin{array}{l}\text { or } " 111 \\
\text { mean }\end{array}$ & S.D. \\
\hline Male & 304 & 85 & \\
\hline Female & 304 & 15 & \\
\hline Mean age (years) & 304 & 55 & 7.2 \\
\hline \multicolumn{4}{|l|}{ Myocardial infarction } \\
\hline Anterior location & 304 & 41 & \\
\hline Inferior location & 304 & 52 & \\
\hline Non-Q-infarction & 304 & 12 & \\
\hline Previous infarction & 304 & 23 & \\
\hline Peak CPK level (I.U./) & 298 & 818 & 155 \\
\hline \multicolumn{4}{|l|}{ Haemodynamic variables } \\
\hline Heart rate (beats/min) & 294 & 75 & 19 \\
\hline $\begin{array}{l}\text { Systolic blood pressure } \\
(\mathrm{mmHg})\end{array}$ & 296 & 135 & 29 \\
\hline $\begin{array}{l}\text { Diastolic blood pressure } \\
\text { (mmHg) }\end{array}$ & 296 & 83 & 16 \\
\hline $\begin{array}{l}\text { Mixed venous oxygen } \\
\text { saturation }(\% / h)\end{array}$ & 262 & 68 & 5.7 \\
\hline Wedge pressure $(\mathrm{mmHg})$ & 261 & 12 & 4.9 \\
\hline Cholesterol $(\mathrm{mmol} / 1)$ & 271 & 6.7 & 1.7 \\
\hline History of hypertension & 293 & 41 & \\
\hline History of smoking & 295 & 74 & \\
\hline Diabetes mellitus & 262 & 6 & \\
\hline
\end{tabular}

${ }_{n} n$. number of patients in whom the characteristic was measured. monary wedge pressure was also included as a categorized variable, with calculation of the relative risks of 10-year mortality. In the multivariate analysis, adjustments were made for differences in age (continuous variable), gender, localisation of infarction (anterior vs. non-anterior), previous infarction, diabetes mellitus, cholesterol (continuous variable), history of hypertension and smoking habits prior to infarction.

Calculation of the survival curve of the general population, matched for age, sex and ycar of observation, was based upon the actual death rates in the Dutch population, provided by the Central Bureau of Statistics on a yearly basis [16].

\section{Results}

Basic characteristics of the study population are summarized in Table 1

Among the 304 patients the 1-, 5- and 10-year cumulative mortality was $6.5 \%, 18.4 \%$ and $35.5 \%$, respectively. The survival curve for the 304 patients is depicted in Fig. 1. During the study period, the yearly average mortality of the general Dutch population, matched for age and sex, was $1.6 \%$ (ranging from $1.1 \%$ to $2.2 \%$ ).

In Table 2, the initial haemodynamic variables of survivors and non-survivors within each of the

$$
\begin{aligned}
& \% \text { survival } \\
& 100- \\
& 80 \\
& 60 \\
& 40 \\
& 20 \\
& 2 \\
& \begin{array}{cccccc}
\text { Years after Myocardial Infarction } &
\end{array} \\
& 9 \quad 10
\end{aligned}
$$

Fig. 1. Survival curves of 304 patients discharged alive after myocardial infarction (dashed line) and the general Dutch population, matched for age, gender and year of observation (solid line). 
Table 2

Comparison of initial haemodynamic variables of patients discharged alive after an acute myocardial infarction. between survivors and non-survivors in each of the time intervals ${ }^{a}$

\begin{tabular}{|c|c|c|c|c|c|c|c|c|c|c|c|}
\hline \multirow[t]{2}{*}{ Time interval } & \multirow[t]{2}{*}{$n^{\mathrm{b}}$} & \multicolumn{2}{|c|}{$\begin{array}{l}\text { Systolic blood } \\
\text { pressure }(\mathrm{mmHg})\end{array}$} & \multicolumn{2}{|c|}{$\begin{array}{l}\text { Diastolic blood } \\
\text { pressure (mmHg) }\end{array}$} & \multicolumn{2}{|c|}{$\begin{array}{l}\text { Heart rate } \\
\text { (beats/min) }\end{array}$} & \multicolumn{2}{|c|}{$\begin{array}{l}\text { Wedge pressure } \\
(\mathrm{mmHg})\end{array}$} & \multicolumn{2}{|c|}{$\begin{array}{l}\text { Venous saturation } \\
(\%)\end{array}$} \\
\hline & & Mean & S.E. ${ }^{c}$ & Mean & S.E. & Mean & S.E. & Mean & S.E. & Mean & S.E. \\
\hline \multicolumn{12}{|l|}{ First year } \\
\hline Survivors & 284 & 136 & 1.7 & 83 & 1.0 & 74 & 1.1 & 12 & 0.3 & 68 & 0.4 \\
\hline Non-survivors & 20 & 121 & 6.4 & 79 & 3.7 & 86 & 4.2 & 17 & 1.1 & 65 & 1.3 \\
\hline$P$ value & & $<0.05$ & & $N S^{d}$ & & $<0.005$ & & $<0.0001$ & & $<0.05$ & \\
\hline \multicolumn{12}{|l|}{$1-5$ years } \\
\hline Survivors & 248 & 136 & 1.8 & 83 & 1.0 & 74 & 1.2 & 11 & 0.3 & 68 & 0.4 \\
\hline Non-survivors & 36 & 134 & 5.0 & 82 & 2.8 & 76 & 3.3 & 14 & 0.8 & 67 & 1.0 \\
\hline$P$ value & & NS & & NS & & NS & & $<0.01$ & & NS & \\
\hline \multicolumn{12}{|l|}{$5-10$ years } \\
\hline Survivors & 194 & 136 & 2.0 & 83 & 1.2 & 74 & 1.3 & 11 & 0.3 & 68 & 0.4 \\
\hline Non-survivors & 52 & 136 & 4.0 & 83 & 2.3 & 76 & 2.6 & 13 & 0.7 & 67 & 0.8 \\
\hline$P$ value & & NS & & NS & & NS & & $<0.005$ & & NS & \\
\hline
\end{tabular}

${ }^{a}$ Adjusted for differences in age and gender.

${ }^{b}$ Corresponds to the total number of survivors and non-survivors in each time interval.

'S.E., standard error.

dNS not statistically significant.

time intervals are compared. With the exception of diastolic blood pressure, all measured haemodynamic parameters were significant predictors of 1year survival. An elevated wedge pressure was the only haemodynamic variable which remained a strong indicator of increased mortality $1-5$, and 5-10 years after discharge.

The multivariate survival analysis showed that after adjusting for differences in age, gender, local-

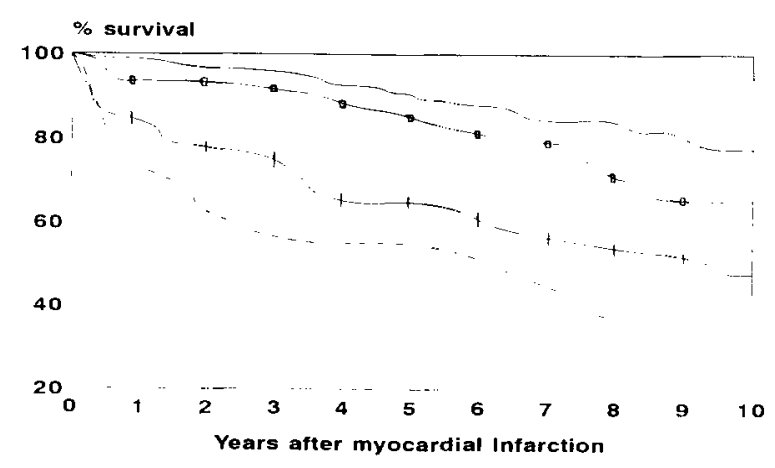

Fig. 2. Kaplan-Meier survival curves of patients after myocardial infarction, with a pulmonary wedge pressure $<12 \mathrm{mmHg}$ (solid line), 12-15 $\mathrm{mmHg}$ (D), $15-19 \mathrm{mmHg}(+)$, and $\geq 19$ $\mathrm{mmHg}$ (dashed line) $(P<0.001)$ isation of infarction, diabetes mellitus, cholesterol level, history of hypertension and smoking habits prior to infarction, a $1-\mathrm{mmHg}$ increase of the pulmonary wedge pressure was associated with a $9 \%$ increase in 10-year mortality (RR, $1.09 / \mathrm{mmHg}$; $95 \%$ confidence interval, 1.04-1.15). The corresponding relative risks in the three non-overlapping time intervals, $0-1,1-5$, and $5-10$ years, were $1.50 / \mathrm{mmHg} \quad(95 \% \mathrm{CI}, 1.10-2.04), 1.05 / \mathrm{mmHg}$

Table 3

Relative risks of 10-year mortality after discharge after acute myocardial infarction, of patients in different categories of pulmonary wedge pressure

\begin{tabular}{lrll}
\hline $\begin{array}{l}\text { Wedge pressure } \\
(\mathrm{mmHg})\end{array}$ & $n^{\mathrm{b}}(\%)$ & $\begin{array}{l}\text { Relative } \\
\text { risk }\end{array}$ & $\begin{array}{l}95 \% \text { Confidence } \\
\text { interval }\end{array}$ \\
\hline$<12$ & $134(51)$ & $1.0^{\mathrm{c}}$ & - \\
$\geq 12$ and $<15$ & $49(19)$ & 2.25 & $1.11-4.55$ \\
$\geq 15$ and $<19$ & $50(19)$ & 2.43 & $1.20-4.92$ \\
$\geq 19$ & $28(11)$ & 2.57 & $1.04-6.37$ \\
\hline
\end{tabular}

adjusted for differences in age, gender, previous infarction, localisation of infarction, diabetes mellitus, cholesterol level, history of hypertension and smoking habits prior to infarction. $b_{n}$ corresponds to the number of patients in each category.

${ }^{\mathrm{c}}$ Reference category. 
(95\% CI, 0.95-1.18) and $1.10 / \mathrm{mmHg}(95 \% \mathrm{CI}$, 1.02-1.18), respectively. An elevated heart rate had a statistically significant influence on 1-year mortality only (relative risk, 1.05/beat per min; $95 \% \mathrm{Cl}, 1.01-1.08$ ). The other haemodynamic variables were not statistically significant predictors of mortality in the multivariate analysis.

To study pulmonary wedge pressure in more detail, wedge pressure was divided into 4 categories: lower than $12 \mathrm{mmHg}, 12-15 \mathrm{mmHg}, 15-19$ $\mathrm{mmHg}$, and $19 \mathrm{mmHg}$ and higher. The unadjusted survival curves of patients in these categories are depicted in Fig. 2. Survival of patients in the three highest categories of wedge pressure was compared with survival of patients in the lowest category. Results of multivariate analysis after 10 years of follow-up are shown in Table 3. Compared with patients in the lowest category $(<12$ $\mathrm{mmHg}$ ), a significant increase of 10-year mortality is demonstrated for all three other categories of pulmonary wedge pressure level.

No J- or U-shaped relationship between pulmonary wedge pressure and mortality could be demonstrated.

\section{Discussion}

This study demonstrates that a single measurement of an elevated pulmonary wedge pressure after acute myocardial infarction may be a strong and independent predictor of both short-term and long-term mortality. Of the other measured haemodynamic variables, systolic blood pressure, heart rate and mixed venous oxygen saturation showed only a weak association with short-term survival only.

Although clinical signs of pulmonary congestion begin at a level of approximately $18 \mathrm{mmHg}$ [17], the generally accepted upper limit of normal is 12 $\mathrm{mmHg}$ [18]. Some previous reports made a distinction between patients with a wedge pressure greater than or equal to $15 \mathrm{mmHg}$ and a wedge pressure lower than $15 \mathrm{mmHg}[8,19]$. We categorized the wedge pressure level in four groups: lower than $12 \mathrm{mmHg}, 12-15 \mathrm{mmHg}, 15-19 \mathrm{mmHg}$, and $19 \mathrm{mmHg}$ and higher. A significant increase of 10 year mortality could be demonstrated in all three groups, compared with those patients with wedge pressure below $12 \mathrm{mmHg}$.

Previous studies demonstrated a significant difference of haemodynamic variables measured early after myocardial infarction between survivors and non-survivors of the hospital period [4,8,9], a few months [9], 2 years [5] and 4 years [7] after discharge. Wolffenbuttel et al. demonstrated a strong association between an elevated pulmonary wedge pressure and increased mortality [7]. Whereas previous studies demonstrated the predictive value within a maximum follow-up period of 4 years, we were able to demonstrate prognostic importance even after a 10-year follow-up period. To our knowledge this report is the first to evaluate long-term prognostic value of haemodynamic variables.

Every patient in the early phase of an acute myocardial infarction has to be regarded as potentially haemodynamically unstable. Pulmonary congestion at the time of an acute myocardial infarction is associated with a poor prognosis [20]. Early recognition and differentiation of the underlying pathology of the pump failure is essential for prompt, appropriate treatment [21]. Methods for classifying patients with acute myocardial infarction, such as proposed by Killip and Kimball [22], have been developed in an effort to define clinically relevant syndromes. This method is readily used at the bedside and has some therapeutic relevance, but the criteria are vague in several respects [23]. Moreover, both clinical signs and the classical chest roentgenogram have limitations in indicating unfavourable haemodynamic changes after acute myocardial infarction [24,25]. SwanGanz catheterisation demonstrates heart failure in absence of clinical or radiological characteristics [8], and facilitates an objective assessment of the level of cardiac performance. For this reason Swan-Ganz catheterisation has been widely used in the acute phase of myocardial infarction. Our study, however, indicates that the measurements during Swan-Ganz catheterisation may be of importance long after the acute phase.

Our study has several limitations. During the period January 1978 to December 1980 all patients admitted with diagnosis of acute myocardial infarction to Zuiderziekenhuis Hospital, Rotterdam, 
routinely received Swan-Ganz catheterisation. In $15 \%$ of the hospital survivors however, SwanGanz catheterisation was not performed, or performed more than $24 \mathrm{~h}$ after admission, mainly because of an uncertain diagnosis in the initial phase. To evaluate whether this may have influenced our findings, the survival curves of patients with and without catheterisation were compared. No difference of the survival curves was demonstrated $(P>0.1)$. Only the mean peak CPK level was significantly higher in patients receiving catheterisation.

The time elapsed from onset of symptoms of myocardial infarction to Swan-Ganz catheterisation could not be calculated in this study since no relevant data were collected. Furthermore, because only a single measurement of the haemodynamic variables was available, regression to the mean or other sources of variability could have diluted the observed associations. A decrease in wedge pressure during the first hours after myocardial infarction was reported in several studies $[5,26]$. The mean of multiple measurements of the pulmonary wedge pressure may be an even stronger indicator of future mortality. Also, varying delay times before recordings of first haemodynamic measurements could have distorted our findings.

We did not identify right ventricular (RV) infarction. $R V$ infarction is associated with a high mortality, although haemodynamic measurements may be normal $[8,27]$. We presume that if patients with RV infarction were excluded, the association of an elevated pulmonary wedge pressure with increased mortality would have been even stronger. However, the clinical incidence of RV infarction has been estimated to be low [28] and thus the effect would have been minimal. Furthermore, we did not identify mitral insufficiency. Mitral insufficiency may cause an artificial elevated wedge pressure [29] and is associated with diminished long-term survival [30]. Hence, a part of the association between an elevated wedge pressure and increased mortality could be caused by mitral insufficiency. Finally, no data on medication administered prior to infarction were available. Drug treatment could have influenced the early measurements, for instance beta blockers affecting the heart rate.
Previous studies demonstrated the safety of Swan-Ganz catheterisation [31]. In current practice however, many patients with acute myocardial infarction receive thrombolytic therapy [32]. These patients are at high risk of developing haemorrhagic complications [33,34], and more than $70 \%$ of bleeding episodes occur at catheterisation of vascular puncture sites [35]. Venous and arterial puncture should be kept to an absolute minimum in patients treated with thrombolytic agents and should be cared for meticulously thereafter [36]. For this reason many physicians are reluctant nowadays to insert a Swan-Ganz catheter in patients on thrombolytic therapy. The question, of course is whether or not the diagnostic and prognostic information from the Swan-Ganz catheterisation justifies the potential bleeding risk in the acute phase. However, a substantial proportion of patients with acute myocardial infarction do not receive thrombolytic therapy $[37,38]$.

Furthermore, after the introduction of thrombolytic therapy, approximately $10 \%$ of the patients with myocardial infarction received Swan-Ganz catheterisation [39]. Moreover, some reports suggest that haemodynamic measurements performed $48 \mathrm{~h}$ or even longer after acute myocardial infarction might be the best reflection of haemodynamic changes [40]. At that time the bleeding risk from thrombolytic agents is less serious.

We conclude that in patients with acute myocardial infarction, early haemodynamic recordings provide short-term prognostic information. Moreover, the pulmonary wedge pressure level, measured shortly after acute myocardial infarction, remains a strong and independent prognostic factor for a period of at least 10 years after infarction. Thus, Swan-Ganz catheterisation after acute myocardial infarction is not only useful in immediate patient management, but also provides prognostic information for years after discharge.

\section{References}

1 Gore JM, Goldberg RJ, Spodick DH, Alpers JS, Dalen JE. A community-wide assessment of the use of pulmonary artery catheters in patients with acute myocardial infarction. Chest 1987; 92: 721-727.

2 Matthay MA, Chatterjee K. Bedside catheterization of the pulmonary artery: risks compared with benefits. Ann Intern Med 1988: 109: 826-834. 
3 Rogers WJ, Smith LR, Oberman A et al. Invasive measurements relating to long-term survival postmyocardial infarction [abstract]. Circulation 1979; 59,60, suppl 11: 232.

4 Verdouw PD. Hagemeijer F, Van Dorp WG, Van der Vorm A, Hughenholtz PG. Short-term survival after acute myocardial infarction predicted by hemodynamic parameters. Circulation 1975; 52: 413-419.

5 Wolffenbuttel BHR, Verdouw PD, Hughenholtz PG. Immediate and two year prognosis after acute myocardial infarction: prediction from non-invasive as well as invasive parameters in the same individuals. Eur Heart $\mathbf{J}$ 1981; 2: 375--387.

6 Martin CA, Thompson PL, Armstrong BK, Hobbs MST, De Klerk $N$. Long-term prognosis after recovery from myocardial infarction: a nine year follow-up of the Perth Coronary Register. Circulation 1983; 68: 961-969.

7 Wolffenbuttel BHR. Verdouw PD, Scheffer MG et al. Significance of haemodynamic variables in coronary care unit for prediction of survival after acute myocardial infarction. Br Heart J 1983; 50: 266-272.

8 Hutchison SJ. Rankin AC. Hutton I. Bedside hemodynamic monitoring in the management of acute cardiac patients. Angiology 1986; 37: 702-708.

9 Held PH, Corbeij HMA, Dunselman P et al. Central haemodynamics in acute myocardial infarction in relation to mortality and peak enzyme activity. Eur Heart J 1986; 7: 475-481.

10 Ottervanger JP, Kruijssen HACM, IIoes AW, Hofman A. De lange-termijn prognose na een hartinfarct: klinische voorspellende variabelen en cardiovasculaire risicofactoren. Ned Tijdschr Geneeskd 1993; 137: 1448-1452.

11 WHO: Regional office for Europe. 5. Myocardial infarction community registers. Geneva, 1976.

12 Swan HJC, Ganz W. Forrester J, Marcus H, Diamond G. Chonette D. Catheterization of the heart in man with use of a flow-directed balloon-tipped catheter. N Engl J Med 1970; 83: 447-451.

13 Flegg HM. An investigation of the determination of serum cholesterol by an enzymatic method. Ann Clin Biochem 1973; 10: 79-84.

14 Kaplan EI, Meier P. Nonparametric estimation from incomplete observations. J Am Stat Assoc 1958; 53: 457-481.

15 Cox DR. Regression models and life tables. J R Stat Soc 1972: 34: 187-220.

16 Central Bureau of Statistics. Age-specific mortality by sex. Vademecum Health Statistics of the Netherlands. 1979-1989, 's Gravenhage, Netherlands.

17 Forrester JS, Diamond G, McHigh TJ et al. Filling pressures in the right and left sides of the heart in acute myocardial infarction. N Engl J Med 1971; 85: 190-193.

18 Forrester JS, Diamond G, Chatterjee K, Swan HJC.. Medical therapy of acute myocardial infarction by application of hemodynamic subsets. N Engl J Med 1976: 295 . 1356-1362.

19 Crexells C. Chatterjee K. Forrester JS, Dikshit K. Swan HJC. Optimal level of filling pressure in the left side of the heart in acute myocardial infarction. N Engl J Med 1973; 289: $1263-1266$.

20 Dwyer EM, Greenberg HM, Steinberg G et al. Clinical characteristics and natural history of pulmonary congestion during acute myocardial infarction. Am J Cardiol 1989: 63: 1423-1428.

21 Daily EK. Use of hemodynamics to differentiate pathophysiologic causes of cardiogenic shock. Crit Care Nurs Clin North Am 1989; 1: 589-602.

22 Killip T, Kimball JT. A survey of the coronary care unit: concept and results. Prog Cardiovasc Dis 1968; 11:45-51.

23 Forrester JS, Diamond GA. Swan HJC. Correlative classification of clinical and hemodynamic function after acute myocardial infarction. Am J Cardiol 1977; 39: $137-145$.

24 Luepker RV. Caralis DG, Voigt GC et al. Detection of pulmonary edema in acute myocardial infarction. Am J Cardiol 1977; 39: 146-152.

25 Kostuk W, Barr JW, Simon AL, Ross J. Correlations between the chest film and hemodynamics in acute myocardial infarction. Circulation 1973; 48: 624-632.

26 Mathey D, Bleifeld W. Hanrath P, Effert S. Attempt to quantitate relation between cardiac function and infarct size in acute myocardial infarction. Br Heart $\mathrm{J} 1974 ; 36$ : 71-79.

27 Candell-Riera J, Figueras J, Valle V et al Right ventricular infarction: relationships between ST segment elevation in $V_{4 R}$ and hemodymamic, scintigraphic, and echocardiographic findings in patients with acute inferior myocardial infarction. Am Heart J 1981; 101: 281-287.

28 Cohn JN, Right ventricular infarction revisited. Am J Cardiol 1979: 43: 666-668.

29 Haskell RJ. French WJ. Accuracy of left atrial and pulmonary artery wedge pressure in pure mitral regurgitation in predicting left ventricular end-diastolic pressure. Am J Cardiol 1988: 61: 136-141.

30 Barzilai B, Davis VG. Stone PH, Jaffe AS and the MILIS Study Group. Prognostic significance of mitral regurgitation in acute myocardial infarction. Am J Cardiol 1990; 65: $1169-1175$.

31 Boyd KD. Thomas SJ. Gold J, Boyd AD. A prospective study of complications of pulmonary artery catheterization in 500 consecutive patients. Chest $1983 ; 84: 242-245$.

32 Bates ER, Topol J. Thrombolytic therapy for acute myocardial infarction. Chest 1989; 95: 257S-264S

33 Meyerovitz MF. How to maximize the safety of coronary and pulmonary angiography in patients receiving thrombolytic therapy. Chest 1990; 97: 132S-135S.

34 Califf RM. Topol EJ. George BS et al. Hemorrhagic complications associated with the use of intravenous tissue plasminogen activator in treatment of acute myocardial infarction. Am J Med 1988; 85: 353-359.

35 Rao AK, Pratt C, Berke A et al. Thrombolysis in myocardial infarction (TIMI) trial -- phase I: hemorrhagic manifestations and changes in plasma fibrinogen and the fibrinolytic system in patients treated with recombinant tissue plasminogen activator and streptokinase. J Am Coll Cardiol 1988: 11: 1-11. 
36 ACC/AHA task force report. Guidelines for the early management of patients with acute myocardial infarction. J Am Coll Cardiol 1990; 16: 249-292.

37 Grines CL, De Maria AN. Optimal utilization of thrombolytic therapy for acute myocardial infarction: concepts and controversies. J Am Coll Cardiol 1990: 16: 223-231.

38 Balagtas R, Herrada J, Bahr R. Thrombolytic therapy in myocardial infarction: a retrospective study. Md Med $J$ 1990; 39: $561-564$.
39 Zion MM, Balkin J, Roseman D. Use of pulmonary artery catheters in patients with acute myocardial infarction. Analysis of experience in 5.841 patients in the SPRINT Registry. Chest 1990; 98: 1331-1335.

40 Zimlichman R, Mossinson D, Ovsyshcher IE. Assessment of hemodynamic changes in the early phase of uncomplicated acute myocardial infarction. Int $J$ Cardiol 1989; 25: 303-311. 